\title{
Article \\ Molecular Genetic Analysis with Microsatellite-like Loci Reveals Specific Dairy-Associated and Environmental Populations of the Yeast Geotrichum candidum
}

\author{
Colin R. Tinsley ${ }^{1,2}$, Noémie Jacques ${ }^{1,+}{ }^{+}$, Marine Lucas ${ }^{1, \ddagger}$, Cécile Grondin ${ }^{1,3}$, Jean-Luc Legras ${ }^{3, *(D)}$ \\ and Serge Casaregola ${ }^{1}$
}

Citation: Tinsley, C.R.; Jacques, N.; Lucas, M.; Grondin, C.; Legras, J.-L.; Casaregola, S. Molecular Genetic Analysis with Microsatellite-like Loci Reveals Specific Dairy-Associated and Environmental Populations of the Yeast Geotrichum candidum. Microorganisms 2022, 10, 103. https: / / doi.org/10.3390/ microorganisms10010103 Academic Editors: Agapi I. Doulgeraki and Chrysoula Tassou

Received: 1 December 2021

Accepted: 27 December 2021

Published: 4 January 2022

Publisher's Note: MDPI stays neutral with regard to jurisdictional claims in published maps and institutional affiliations.

Copyright: (C) 2022 by the authors. Licensee MDPI, Basel, Switzerland. This article is an open access article distributed under the terms and conditions of the Creative Commons Attribution (CC BY) license (https:// creativecommons.org/licenses/by/ $4.0 /)$.
1 Micalis Institute, INRAE, AgroParisTech, Université Paris-Saclay, 78350 Jouy-en-Josas, France; colin.tinlsey@agroparistech.fr (C.R.T.); Noemie.Jacques@inrae.fr (N.J.); Marine.Lucas@inrae.fr (M.L.); Cecile.Grondin@inrae.fr (C.G.); Serge.Casaregola@inrae.fr (S.C.)

2 Unité Microbiologie et Génétique Moléculaire, Department des Sciences de la Vie et Santé, AgroParisTech, 16 Rue Claude Bernard, 75005 Paris, France

3 SPO, Université de Montpellier, INRAE, Institut Agro, 34000 Montpellier, France

* Correspondence: jean-luc.legras@inrae.fr

† Current address: Université Paris-Saclay, INRAE, UR BIOGER, 78850 Thiverval-Grignon, France.

$\ddagger$ Current address: Microflora, Institut des Sciences de la Vigne et du Vin, 210 Chemin de Leysotte, CEDEX CS50008, 33882 Villenave d'Ornon, France.

\begin{abstract}
Geotrichum candidum is an environmental yeast, also found as part of the cheese surface microbiota, where it is important in the ripening of many traditional cheeses, such as Camembert. We have previously developed a Multi Locus Sequence Typing (MLST) scheme, which differentiated five clades, of which one contained only environmental isolates, two were composed almost entirely of dairy isolates, and two others contained a mixture of dairy, environmental, and miscellaneous food isolates. In order to provide a simple method to uniquely type G. candidum strains, and in addition to permit investigation of the population structure at a fine level, we describe here a molecular analysis using a set of twelve highly discriminating microsatellite-like markers. The present study consolidates the previously suggested division between dairy and environmental strains, and in addition distinguishes a specifically European group of environmental strains. This analysis permitted the discrimination of 72 genotypes from the collection of 80 isolates, while retaining the underlying meaningful phylogenetic relation between groups of strains.
\end{abstract}

Keywords: Geotrichum candidum; adaptation; environment; dairy

\section{Introduction}

The dimorphic yeast Geotrichum candidum (teleomorph Galactomyces candidus) is an environmental species commonly found in foodstuffs, where it is present either as part of the technological microbiota, as in cheeses, or as a spoilage microorganism, and in addition is of interest as a source of enzymes (lipases, etc.) for biotechnological applications (reviewed in [1-3]). Owing to its propensity for filamentous growth, it was long considered as a fungus, as shown by the many names applied to this species since its description in 1809 by Link [4]. Its phylogenetic position has only recently been stabilized. Comparative genomic analysis has unambiguously assigned G. candidum to the Saccharomycotina subphylum [5]. In this study, genome analysis showed that G. candidum has specifically retained over 250 genes during evolution, some of which may partly explain its filamentous phenotype. In addition, this genome sequence analysis revealed a number of interesting genes which may be useful for biotechnology [6].

Due to the importance of G. candidum in the agrofood- and bio-industries, the population structure of this species has been the subject of considerable research. Based on the study of 62 isolates, it was shown that G. candidum displays significant polymorphism 
in its rDNA sequence, and 32 different sequences could be defined [7]. Intra-specific diversity was further studied in an MLST analysis involving 40 isolates, which defined distinct populations, some being specifically associated with cheese-making. In this publication, a correlation was found between two of these populations and categories of rDNA sequences [8], suggesting that rDNA sequence comparison may be used for structuring populations in this species. A more recent MLST analysis involving 67 isolates also defined distinct populations [9], one of these being composed exclusively of environmental strains. In addition, this analysis distinguished two types of dairy strains, one forming a homogeneous group with little genetic diversity, and the other more closely related to environmental isolates. Overall, this ensemble of results provides evidence suggesting an adaptation of G. candidum to the cheese-making environment.

Microsatellite analysis has proven to be a method of choice for molecular typing of yeast. The work of Legras and colleagues [10] established distinct groups of Saccharomyces cerevisiae directly linked to their different uses in biotechnology, which more recently has been supported by complete genome sequencing [11,12]. Since the mid-2000s, a number of studies have used this technique on food yeasts to study interspecies diversity [13], to distinguish populations [14-17], to show correlation between phenotypic and genotypic characteristics, or to bring to light correlations between geographic and genotypic characteristics [18-21].

Here, we selected a set of polymorphic trinucleotide motif-rich regions and apply a typing scheme using these microsatellite-like markers to the collection of isolates previously analysed by MLST and inter-LTR PCR typing [9], and show that we can clearly distinguish strains associated with cheese from those isolated in natural environments. Overall, our results strongly support a model whereby certain groups of G. candidum strains have been domesticated in cheese production and have since evolved separately from naturally occurring isolates.

\section{Materials and Methods}

\subsection{Yeast Isolates and Growth Conditions}

Isolates used in this study are listed in Table 1 and have been isolated in former projects. Thirty-nine of the 80 isolates (isolates prefixed "CNRZ" or "CLIB") were from the CIRMLevures Biological Resource Center, INRAe Montpellier, France; https: / / cirm-levures.bioaware.com/ (accessed on 3 March 2020)). Twenty "FM" isolates were provided as part of the "Food Microbiomes" project (Agence National de la Recherche, France; ANR-08-ALIA-0007) by various industrial enterprises; information is available concerning the origins of 13 of these isolates, seven were anonymized in accordance with certain enterprises' confidentiality policies. Other isolates were from the Westerdijk Institute (Utrecht, The Netherlands), the University of Caen (France), the Museum National d'Histoire Naturelle (Paris, France), VTT Technical Research Center (Finland), Kasetsart University (Bangkok, Thailand), the DSMZ-(Braunschweig, Germany), the BCCM/MUCL (Louvain la Neuve, Belgium), the NCYC (Norwich, United Kingdom), or the NITE (Chiba, Japan). Yeast strains were grown in YPD medium (Yeast Peptone Dextrose: yeast extract $10 \mathrm{~g} \mathrm{~L}^{-1}$, bacto peptone $10 \mathrm{~g} \mathrm{~L}^{-1}$, glucose $10 \mathrm{~g} \mathrm{~L}^{-1}$ ) at $28{ }^{\circ} \mathrm{C}$ with shaking. For solid medium, agar was added to YPD medium at $1.4 \% w / v$.

\subsection{DNA Extraction}

The procedure used the "Nucleospin Plant II" kit (Macherey-Nagel, Hoerdt, France) with certain modifications, necessary for breaking down the resistant yeast cell walls. Cultures grown in $20 \mathrm{~mL}$ of YPD medium overnight at $28{ }^{\circ} \mathrm{C}$ were sedimented by centrifugation at $2500 \mathrm{~g}$ for $3 \mathrm{~min}$. The cell pellets were washed in $5 \mathrm{~mL}$ of $10 \mathrm{mM}$ EDTA, $\mathrm{pH} 8$, and suspended in $3 \mathrm{~mL}$ of sorbitol buffer (1.2 M sorbitol, $100 \mathrm{mM}$ EDTA-Na, $100 \mathrm{mM}$ Tris-HCl, $35 \mathrm{mM}$ beta-mercaptoethanol, $\mathrm{pH} 8$ ) to which were added 50 units of zymolyase (Amsbio, Abingdon, UK). After incubation for $1 \mathrm{~h}$ at $37^{\circ} \mathrm{C}$, the cells were sedimented and the pellet suspended in $2 \mathrm{~mL}$ of lysis buffer according to kit manufacturer's protocol. Digestion with $1 \mathrm{mg}$ of proteinase $\mathrm{K}$ was carried out at $56^{\circ} \mathrm{C}$ for $3 \mathrm{~h}$, then the temperature 
was increased to $65^{\circ} \mathrm{C}$ before addition of $250 \mu \mathrm{g}$ of RNase A and incubation for a further $15 \mathrm{~min}$. DNA purification was performed according to the manufacturer's protocol, and the resulting genomic DNA was dissolved in $300 \mu \mathrm{L}$ of TE buffer (10 mM EDTA-Na, $10 \mathrm{mM}$ Tris- $\mathrm{HCl}, \mathrm{pH}$ 8) containing $0.4 \mu \mathrm{g} \mathrm{mL} \mathrm{m}^{-1} \mathrm{RNase}$. The quality of the DNA preparation and its approximate concentration were estimated by agarose gel electrophoresis.

\subsection{Loci Selection}

In order to detect microsatellite, we searched for genomic enriched for specific trinucleotides using the program "Tandem Repeats Finder" v. 4.07b (TFR; Gary Benson, Boston University). While some of these loci were clear microsatellite loci, others did not present perfect microsatellite stretches, but were nonetheless seen to be polymorphic. Repeats between 100 and 400 bases in length in the index sequenced strain (CLIB 918) were selected, and those giving polymorphic amplicons between 100 and 500 bases in length in the tested strains were retained. Of the 13 loci identified by "Tandem Repeats Finder", twelve were retained, the locus ML069 being of limited diversity with only 6 alleles in the populations studied (Table S1, Figure S1).

\subsection{PCR Amplification}

The primers used in this study were designed with Primer3 (http:/ / fokker.wi.mit.edu/ primer3, (accessed on 3 September 2014)) based on the sequences flanking microsatellitelike loci determined in the sequence of G. candidum [5] (Table S1). Multiplex PCRs were performed with primer mixes: (B3/B4, B5/B6, D1/D2, E5/E6, G7/G8), (A3/A4, A7/A8, D3/D4, F7/F8), and (A5/A6, I3/I4, I5/I6, F1/F2). Amplification used the enzyme Ex-Taq (TaKaRa) under the manufacturer's recommended conditions with a cycle of $94{ }^{\circ} \mathrm{C}$ for $4 \mathrm{~min}$, followed by 30 cycles of $94{ }^{\circ} \mathrm{C}$ for $30 \mathrm{~s}, 60^{\circ} \mathrm{C}$ for $30 \mathrm{~s}$, and $72{ }^{\circ} \mathrm{C}$ for $40 \mathrm{~s}$. The program was terminated by $5 \mathrm{~min}$ at $72{ }^{\circ} \mathrm{C}$. Fragment lengths were measured with a Beckman Coulter CEQ 8800 Genetic Analysis System.

\subsection{Data Treatment}

Measured amplicon lengths were converted to integer numbers of bases by an inhouse clustering algorithm (Tables S2 and S3), then phylogenetic analysis was performed using the model of Edwards and Cavalli-Sforza [22-24] as implemented in the package "PoppR" in " $R$ " $[24,25]$. It was not possible to distinguish haploid from diploid states in cases where a single band was produced from a given primer pair. Hence, data from the strains which only produced a single band per primer pair were converted to a "diploid" state by creating a second allele identical to the first.

As an alternative approach, one thousand "haploid" genotypes were created for each isolate by choosing with equal probability one of the two alleles at each locus for heterozygous loci or taking the unique allele in the case of haploid (homozygous) loci. One thousand neighbor-joining (NJ) trees were produced (1000 bootstraps per tree) and an average consensus tree was created by the phylogenetic program suite, "Mega X" [26].

Detection of the population structure was performed with "Instruct" [27]. The outputs of 27 runs were combined, and the best partitioning was determined as proposed by the program "CLUMPP" [28].

A comparison of results of the present study with those from MLST analysis [9] was performed with the Mantel test [29] implemented in " $R$ " and by the online algorithm "Icong" (http://max2.ese.u-psud.fr/icong/index.help.html, (accessed on 10 March 2021)) [30]. The Pearson correlation between the two distance matrices was calculated in $R$, using the function "cor".

\section{Results and Discussion}

The 80 isolates analyzed include the 64 previously studied by MLST analysis [9], with the addition of 16 further isolates specific to this study. The panel comprised 47 isolates from a dairy or cheese-making environment (the isolates from human stools were considered 
to be in this category), 18 environmental isolates from domestic, agricultural, or natural contexts, and 14 of unknown origin (Table 1).

Table 1. Strains used in this study.

\begin{tabular}{|c|c|c|c|c|c|}
\hline Isolate Name & Substrate of Isolation & Geographical Origin & Mating Type ${ }^{a}$ & $\begin{array}{l}\text { MLST Sequence } \\
\text { Type }^{b}\end{array}$ & $\begin{array}{l}\text { MLST Clonal } \\
\text { Complex }^{b}\end{array}$ \\
\hline CBS 178.71 & Soil polluted with oil & Germany & MATA/MATB & nd & nd \\
\hline CBS 182.33 & Yoghurt & Italy & MATB & 6 & 2 \\
\hline CBS 476.83 & Soil & Senegal & nd & 34 & 4 \\
\hline CBS 557.83 & Peach & Egypt & nd & 35 & 4 \\
\hline CBS 615.84 & Brie cheese & France & MATB & 20 & 3 \\
\hline CBS 9194 & Fruitfly & Brazil & MATA & 8 & 3 \\
\hline CBS 11176 & Bryndza cheese & Slovak republic, Žilina & MATB & 19 & 5 \\
\hline CBS 11628 & Soil & $\begin{array}{c}\text { South Africa, Western } \\
\text { Cape }\end{array}$ & nd & 33 & 4 \\
\hline CBS 117138 & Compost & Italy & nd & 14 & 3 \\
\hline CLIB 918 & Pont-l'Évêque cheese & France, Calvados & MATA & 28 & 5 \\
\hline CLIB 1154 & Flower & France, French Guiana & nd & nd & nd \\
\hline CLIB 1235 & Camembert cheese & France, Orne & MATA & 5 & 1 \\
\hline CLIB 1236 & Goat's cheese & France, Manche & MATA & 7 & 1 \\
\hline CLIB 1237 & Cow milk & France, Orne & MATA & 3 & 2 \\
\hline CLIB 1239 & Mont d'Or cheese & France, Doubs & MATA & 29 & 5 \\
\hline CLIB 1240 & Reblochon cheese & France, Haute-Savoie & MATB & 22 & 5 \\
\hline CLIB 1241 & Mont d'Or cheese & France, Doubs & MATA & 29 & 5 \\
\hline CLIB 1242 & Reblochon cheese & France, Haute-Savoie & MATA & 22 & 5 \\
\hline CLIB 1243 & Reblochon cheese & France, Haute-Savoie & MATA & 22 & 5 \\
\hline CLIB 1244 & Tomme de Savoie cheese & France, Haute-Savoie & MATB & 30 & 5 \\
\hline CLIB 1245 & Reblochon cheese & France, Haute-Savoie & MATA & 30 & 5 \\
\hline CLIB 1246 & Reblochon cheese & France, Haute-Savoie & MATB & 30 & 5 \\
\hline CLIB 1247 & Tomme de Savoie cheese & France, Haute-Savoie & MATB & 30 & 5 \\
\hline CLIB 1248 & Reblochon cheese & France, Haute-Savoie & MATA & 19 & 5 \\
\hline CLIB 1249 & Mont d'Or cheese & France, Doubs & MATA/MATB & nd & nd \\
\hline CLIB 1251 & Epoisses cheese & France, Côte-d'Or & MATA & 7 & 1 \\
\hline CLIB 1252 & Epoisses cheese & France, Côte-d'Or & MATA & 7 & 1 \\
\hline CLIB 1253 & Reblochon cheese & France, Haute-Savoie & MATB & 30 & 5 \\
\hline CLIB 1254 & Reblochon cheese & France, Haute-Savoie & MATA/MATB & nd & nd \\
\hline CLIB 1255 & Reblochon cheese & France, Haute-Savoie & MATA & 22 & 5 \\
\hline CLIB 1256 & Reblochon cheese & France, Haute-Savoie & MATA & 29 & 5 \\
\hline CLIB 1257 & Saint Nectaire cheese & France, Puy-de-Dôme & MATA & 21 & 5 \\
\hline CLIB 1258 & Saint Nectaire cheese & France, Puy-de-Dôme & MATB & 14 & 3 \\
\hline CLIB 1260 & Saint Nectaire cheese & France, Puy-de-Dôme & MATA & 19 & 5 \\
\hline CLIB 1262 & Saint Nectaire cheese & France, Puy-de-Dôme & MATA & 29 & 5 \\
\hline CLIB 1263 & Saint Nectaire cheese & France, Puy-de-Dôme & MATB & 7 & 1 \\
\hline CLIB 1267 & Chaource cheese & France, Aube & MATA & 2 & 2 \\
\hline CLIB 1270 & Saint Nectaire cheese & France, Puy-de-Dôme & MATA & 29 & 5 \\
\hline CLIB 1274 & Reblochon cheese & France, Haute-Savoie & MATB & 16 & 5 \\
\hline CLIB 1283 & Pont-l'Évêque cheese & France, Calvados & MATB & 10 & 3 \\
\hline CLIB 1284 & Raw cream & France, Calvados & MATA/MATB & nd & nd \\
\hline CLIB 1285 & Livarot cheese & France, Calvados & MATA & 25 & 5 \\
\hline CNRZ 818 & unknown & unknown & nd & nd & nd \\
\hline CNRZ 819 & unknown & unknown & nd & nd & nd \\
\hline CNRZ 820 & unknown & unknown & nd & nd & nd \\
\hline CNRZ 821 & unknown & unknown & nd & nd & nd \\
\hline CNRZ 822 & unknown & unknown & nd & nd & nd \\
\hline CNRZ 823 & unknown & unknown & nd & nd & nd \\
\hline DSM 10452 & Sauerkraut & Germany & nd & 31 & 1 \\
\hline DSM 13629 & Polyurethane & United Kingdom & nd & 38 & 3 \\
\hline EL13-B1-3 & Refrigerator & France & nd & nd & nd \\
\hline FM 03 & Cheese contaminant & unknown & MATB & 12 & 3 \\
\hline FM 12 & unknown & unknown & nd & nd & nd \\
\hline FM 29 & Cheese & Auvergne & МАТВ & 23 & 5 \\
\hline FM 30 & Cheese & Auvergne & MATB & 24 & 5 \\
\hline FM 31 & Cheese & Auvergne & MATB & 23 & 5 \\
\hline FM 34 & Goat's cheese & Auvergne & MATA & 18 & 5 \\
\hline FM 76 & Raw milk & France, Normandie & MATB & 18 & 5 \\
\hline FM 77 & unknown & unknown & MATB & 18 & 5 \\
\hline
\end{tabular}


Table 1. Cont.

\begin{tabular}{|c|c|c|c|c|c|}
\hline Isolate Name & Substrate of Isolation & Geographical Origin & Mating Type ${ }^{\text {a }}$ & $\begin{array}{c}\text { MLST Sequence } \\
\text { Type }^{b}\end{array}$ & $\begin{array}{l}\text { MLST Clonal } \\
\text { Complex }\end{array}$ \\
\hline FM 115 & unknown & unknown & MATB & 26 & 3 \\
\hline FM 119 & unknown & unknown & MATA/MATB & nd & nd \\
\hline FM 122 & unknown & unknown & MATA & 9 & 3 \\
\hline FM 125 & unknown & unknown & MATA & 7 & 1 \\
\hline FM 136 & unknown & unknown & MATA & 14 & 3 \\
\hline FM 212 & Corn silage & France & MATB & 13 & 3 \\
\hline FM 213 & unknown & unknown & MATA/MATB & nd & nd \\
\hline FM 214 & Milk & France, Normandie & MATA & 18 & 5 \\
\hline FM 267 & Stools & France, Normandie & MATA/MATB & nd & nd \\
\hline FM 268 & Stools & France, Normandie & MATA & 18 & 5 \\
\hline FM 269 & Stools & France, Normandie & MATA & 27 & 5 \\
\hline FM 270 & Stools & France, Normandie & MATA & 11 & 3 \\
\hline LCP 51.590 & Sand & Spain, Burgos & MATA & 4 & 2 \\
\hline MUCL 881 & Milk & Belgium, Flemish Region & nd & 22 & 5 \\
\hline MUCL 8652 & Wet hay & Belgium, Flemish Region & nd & 37 & 3 \\
\hline MUCL 11539 & Polluted water & Great Britain & nd & 32 & 3 \\
\hline MUCL 14462 & Squash & USA, Pierce county & nd & 39 & 3 \\
\hline NBRC 5368 & Butter & Great Britain & nd & 36 & 3 \\
\hline NCYC 49 & Milk & Great Britain & nd & 40 & 1 \\
\hline NT 12 & Rain forest & Thailand & MATB & 1 & 2 \\
\hline VTTC 4559 & Malting & Sweden & MATB & 15 & 3 \\
\hline
\end{tabular}

nd: not determined; a: Mating type according to Morel [31]; b: MLST types and clonal complexes are according to Jacques and colleagues [9].

The genome of strain G. candidum CLIB 918 (=ATCC 204307 [5]) was used to search for microsatellite loci. As markers, we chose twelve microsatellite-like regions rich in trinucleotide repeats giving amplicons between 100 and 500 bases in length, hence suitable for phylogenetic analysis (Table S1). Amplicon lengths corresponding to each of the markers with each of the isolates are shown in Tables S2 and, after clustering of the data to groups separated by integer base lengths, S3. Three of the isolates, CBS 178.71, CBS 615.84, and FM119 gave two PCR products with several (respectively 4, 4, and 7) of the primer pairs, and seven others gave two PCR products with one of the primer pairs, while the rest gave one amplicon (see Tables S2 and S3). Since it was not possible to discriminate the haploid from diploid homozygous states on the basis of these data, we treated all isolates as diploids.

Figure 1 shows the neighbor-joining (NJ) tree resulting from analysis of the chosen microsatellite markers. This analysis discriminated 72 genotypes from the set of 80 isolates. The most important cluster of identical genotypes contained strains CLIB 1242, CLIB 1243, CLIB1253, and CLIB 1255 that were isolated on "Reblochon" cheese from two different factories separated by $15 \mathrm{~km}$. The second cluster contained strains CLIB 1244, CLIB 1245, and CLIB 1247 isolated on "Reblochon" and "Tome de Savoie" cheeses in another factory, at a 15-km distance from the former two. A third pair of identical genotypes, CLIB 1251 and CLIB 1252, were isolated from "Epoisses" cheese in the same cheese factory. In contrast, CLIB 918 and CLIB 1262 had been isolated from "Pont 1'Evêque" and "Saint Nectaire" cheeses in different regions of France, and the anonymization of the former of the FM12, CLIB 1240 pair prevents us from investigating their respective localizations. We note that most strains were not closely related, which suggests that they did not derive from few starter cultures. Indeed, we can expect that the use of starter cultures would lead to the presence of many groups of identical or very closely-related strains in the phylogram of Figure 1, in opposition to the diversity that is observed. This is in accordance with the period of isolation of CLIB and CNRZ strains, 20 to 30 years ago, when commercial ripening starters were not used for cheese making. 


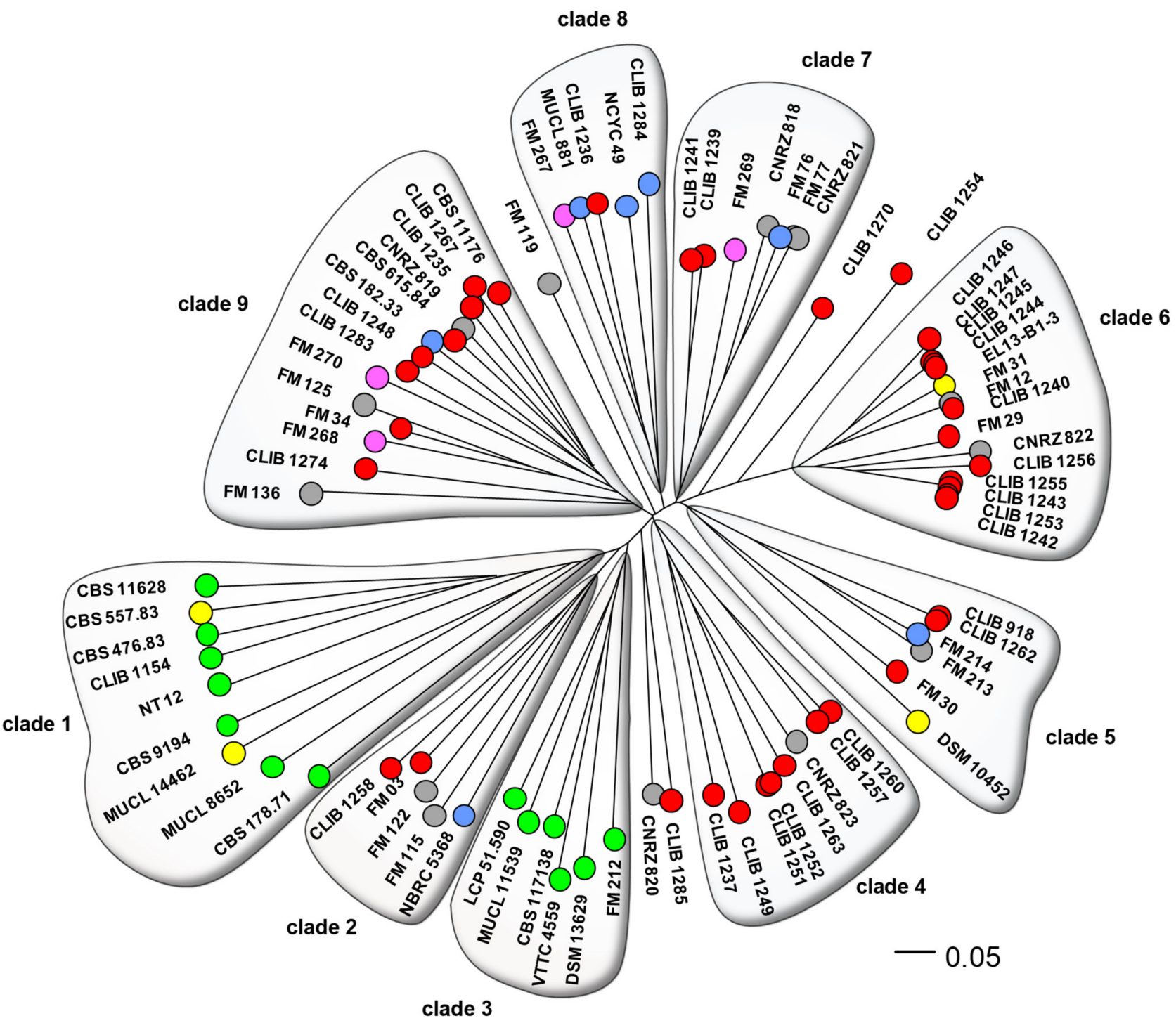

Figure 1. Dendrogram of the G. candidum strains. Phylogeny of the 80 isolates was calculated by the neighbor-joining algorithm using distances calculated according to Edwards and Cavalli-Sforza [22]. Genotypes are represented by coloured circles, according to the isolates' origins: red, cheese; blue, milk; pink, human stools; yellow, foodstuffs; green, environmental; grey, origin unknown.

Overall, there is a clear distinction between environmental and cheese or other dairy isolates. Clades 1 and 3 contained exclusively environmental isolates (OTUs coloured green in Figure 1) or those from non-dairy foodstuff (OTUs coloured yellow). The two "food" isolates within one of these clades, CBS 557.83 and MUCL 14462, were respectively from peach and from squash, and can reasonably be assimilated to environmental isolates, since fruit is one of the natural habitats of G. candidum [32]. Clade 3 contained environmental strains exclusively of european origin, compared to the mostly non-european origins of the strains in clade 1. The other clades contained a mixture of cheese, human stool (very probably originating from dietary cheese), and dairy strains, with the exception of two isolates from food. Strains DSM 10452 was isolated from sauerkraut [33], while EL-13-B1-3 (origin given as 'refrigerator') may have been a contaminant originating from cheese (Figure 1). Isolates of unknown origin (CNRZ 818 to 823 and seven anonymized G. candidum of the "FM" group) were distributed throughout the phylogram, excepting the environmental clades. As these CNRZ strains are from a historic INRAE culture collection dedicated to dairy product microorganisms, it is logical to see them clustered with those 
from other dairy products. A similar situation can be seen for the anonymized isolates of the "Food microbiome" project that are also associated with dairy clades. There was no noticeable generalized clustering of strains according to cheese type or place of origin.

The five isolated strains (CLIB 1254, CLIB 1270, CLIB 1285, CNRZ 820, and FM 119) outside of the defined clades may represent poorly sampled clades. They might otherwise contain genetic material from two different sources, intermediate strains as seen in Saccharomyces cerevisiae [11,34]. Investigation showed that, excepting strain CLIB 1254 which harbored rare alleles at four of the twelve loci, these strains indeed contained mostly a mixture of alleles from the adjacent clades (Table S3).

It is interesting to compare the results of the present study with those of Morel, since the ploidy of about half of the strains has previously been inferred by analysis of the MAT locus. In the present work, three of the isolates (CBS 178.71, CBS 615.84, and FM 119) gave two PCR products for four or more of the 13 loci, and were considered very probably diploid. Another seven (CLIB 1235, CLIB 1249, CLIB 1254, EL13-B1-3, FM 213, FM 267, and MUCL 11539) gave two bands for only one of the loci, equivocal evidence for a diploid state since a local duplication would give the same result. Results for the analysis of the MAT loci are given in Table 1. Strains CBS 178.71, CLIB 1249, CLIB 1254, and CLIB 1284 were inferred to be diploid, since they carry both the MATA and MATB alleles, while another 36 are very probably haploid, being either MATA or MATB. Of the four afore-mentioned MATA/MATB strains, one (CLIB 1284) gave only one band for each of the 13 loci tested and the three others gave two bands for at least one microsatellite locus. These results were consistent with a diploid state, CLIB 1284 possibly being a result of mating between two closely related strains. Of the 36 strains possessing one only of $M A T A$ or $M A T B$, two gave discordant results in this study: CLIB 1235 was apparently diploid for one locus, while CBS 615.84 gave two PCR products for four of the 13 loci and hence was very likely a diploid strain. The result for CLIB 1235 may be due to a partial duplication of the locus followed by mutation, or an introgression of DNA carrying the locus from another strain. The case of CBS 615.84 is more interesting, since it is the anamorphic type strain of the G. candidum species, perhaps indicating that the strain results from a mating followed by loss or erosion of one of the mating type loci.

Since we had a mixture of haploid and isolates strains, a second approach was used to consolidate the primary results. We calculated a consensus tree on the basis of 1000 rounds of random sampling of the alleles at each locus (Figure S2). This phylogram differed in some details from the tree shown in Figure 1, but produced the same clades as those previously defined and similarly separated environmental clades 1 and 3 from the other, cheese and dairy, clades with bootstrap values of 100 and $88 \%$, respectively. The lower average values for bootstrap for the tree, compared to those observed with MLST [9], may result from the small number of loci (12 here) in comparison to the higher number of variable characters considered in an MLST study, as has been observed in other studies, which used less stringent resampling techniques $[10,18]$. Thus, these results support the robustness of both of the techniques for analysis of yeasts of mixed ploidy.

We compared the results obtained with this set of microsatellite-like markers with those that we had obtained previously by MLST [9]. The Pearson correlation coefficient between the genetic distance matrices calculated from the MLST and from the microsatellite data was 0.58 and the similarity between the two distance matrices, as determined with the Mantel test, was significant at $p=0.0001$. Another approach, comparing the topologies of the NJ trees (Icong [30]) gave a significance at $p=0.0007$. The trees are represented face to face in Figure 2, demonstrating an overall similarity between the MLST and microsatellite phylogenies. In the previous work (phylogram on the right of the figure), two MLST clades, 1 and 5, contained the large majority of dairy isolates, while clades 3 and 4 corresponded mostly to environmental isolates. Isolates of the MLST clades 3, 4 (environmental), and 5 (dairy) were distinguished by the present microsatellite analysis, though the MLST dairy clades 1 and 2 were not defined here but rather redistributed within the phylogeny. Indeed, there is a good correlation between the MLST clades 3 and 4 and the environmental 
clades, 1 and 3, of the present study (Figure 2), and the two environmental strains of the MLST clade 2 (LCP 51.590 and NT12) are grouped by the present study together with the other environmental isolates. In addition, three dairy strains (FM270, CLIB 1283, and CBS 615.84) from MLST environmental clade 3 were more coherently placed by the present microsatellite analysis in clades together with other dairy isolates.
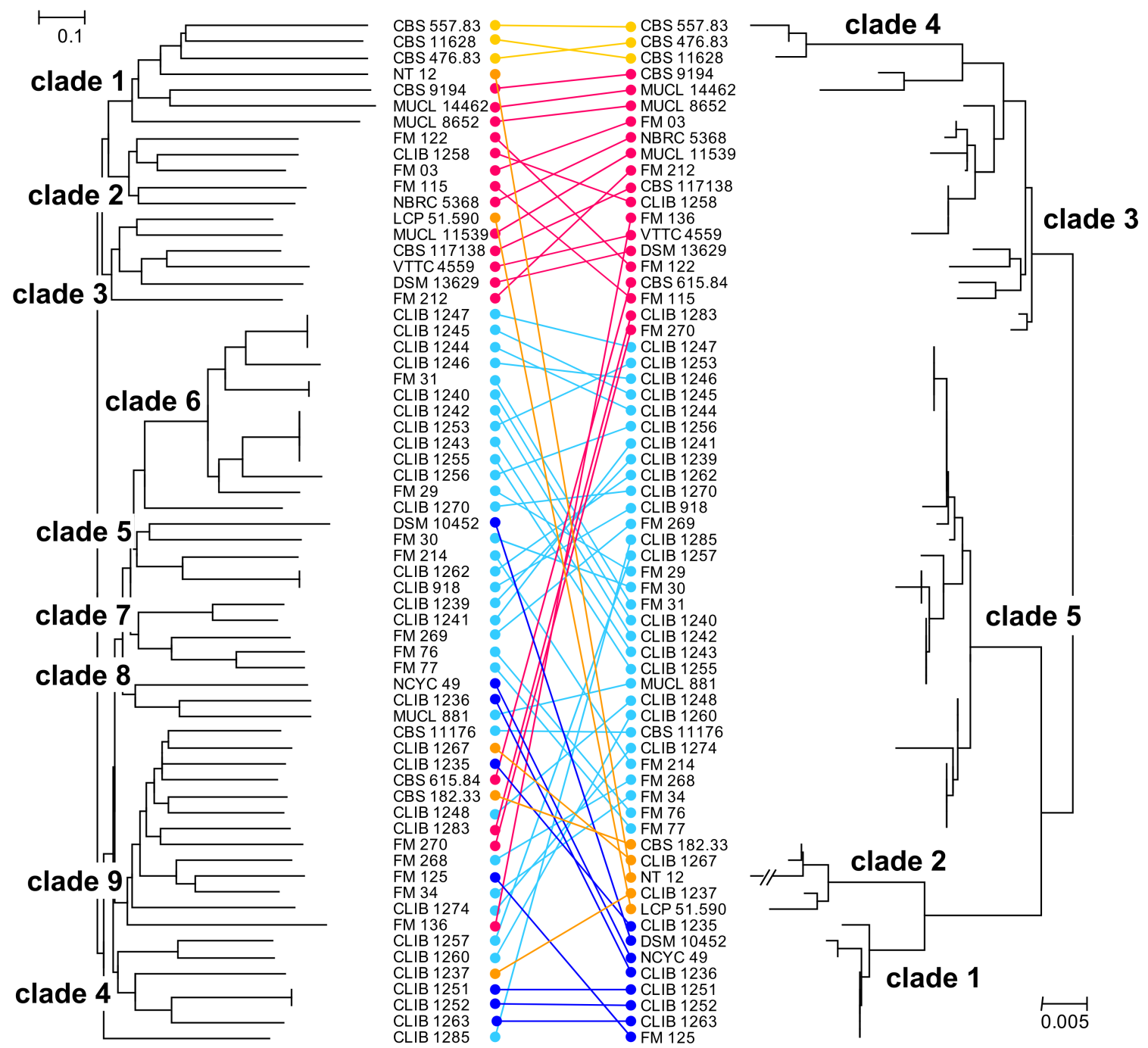

Figure 2. Comparison of NJ trees obtained by analysis of the microsatellite-like loci and MLST analyses of the G. candidum strains. Left, microsatellite analysis; right MLST analysis [9]. Taxon order was optimized manually using "Mega X" and strains that were not common to the two studies were removed. Connectors are coloured with respect to the MLST clades: dark blue, clade 1; orange, clade 2; pink, clade 3; yellow, clade 4; turquoise, clade 5.

The extent of sexual reproduction is not known in this species, although the reticulated tree obtained from a previous MLST analysis revealed a number of genetic exchanges between the strains analyzed [9,31]. To account for genetic exchanges, we analysed the data using the program "Instruct" [27]. Based on the "Structure" algorithm [35], but not making the assumption of free mating and allowing populations to be inbred, the algorithm calculates the proportions of the genetic composition of an individual, which is derived from each of a number of hypothetical ancestral populations, the constitution and number, $K$, of these ancestral populations was estimated to maximize the prior probability of the model. Testing various values of $K$ gave a cutoff value of 6 , above which no significant increase in probability was seen. We conclude that the data are best explained by the 
existence of six ancestral populations. Results are shown in Figure 3, which also presents a comparison with the results from the NJ distance tree. The grouping of the isolates was similar in the two analyses. The environmental NJ clade 1 was separated from the others in the "Instruct" analysis, and furthermore split into two subgroups (groups predominantly deep blue and green in the upper part of Figure 3). However, neighbor-joining clades 2 and 3 were grouped together ("Instruct" cluster indicated in pink), leading to a less complete separation of environmental and dairy isolates.

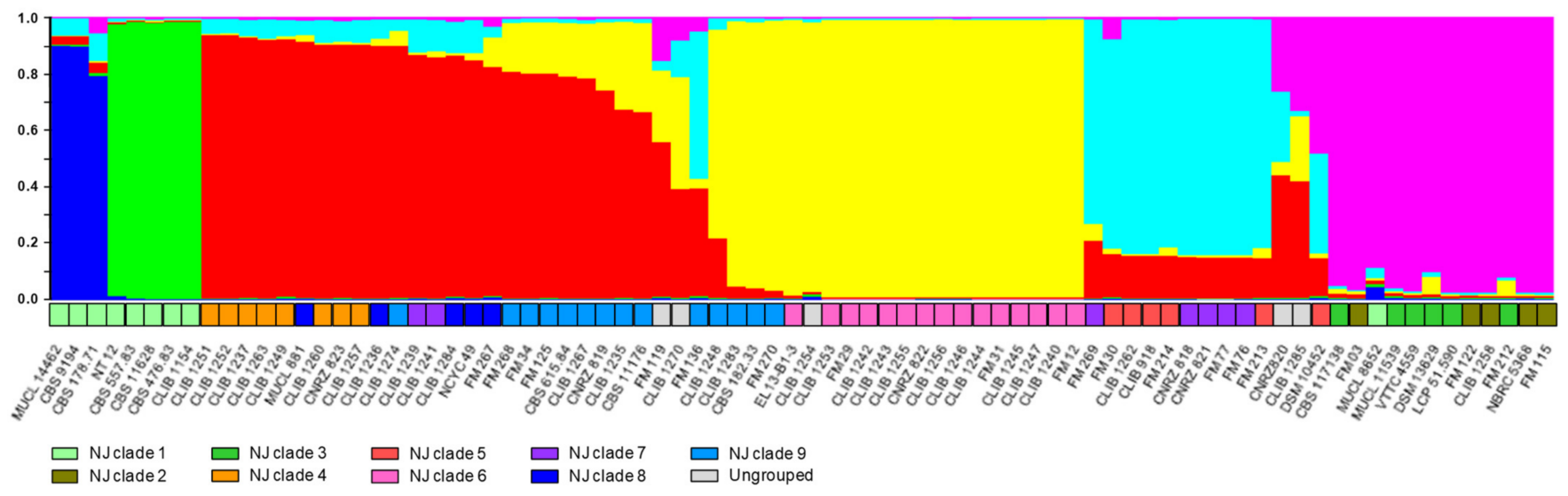

Figure 3. Analysis of microsatellite data and clustering of the G. candidum strains by "Instruct". Colours of the histogram columns represent the proportion of the genetic constitution of an individual derived from each of the six hypothetical ancestral populations. For comparison with the analysis presented in Figure 1, the panel immediately above the isolates' names shows the clades defined previously: light green, clade 1; khaki, clade 2; green, clade 3; orange, clade 4; red, clade 5; pink, clade 6; purple, clade 7; dark blue, clade 8; turquoise, clade 9; grey, strains not associated with named clades in the previous figure.

A distinction between dairy and environmental strains is in agreement with the results of previous studies using RAPD [36] or MLST [8,37]. In our study, involving a large number of environmental isolates, it is interesting that the methods described all divided these isolates into the same two clades. This phylogenetic distance may represent geographical separation, since isolates belonging to clade 2 are all European, whereas those from clade 1, were mainly isolated in non-European countries (Africa, the Americas, and south-east Asia). Indeed, Table S4 shows that the former group contains a large majority of rare alleles at each of the loci, underlining their genetic distance from the other strains, including those environmental strains isolated in Europe. In support of the geographical explanation are the relatively large distances between strains of the non-European group, though no consistent subdivision on geographical bases is evident. The distance between the environmental and dairy clades seen in Figure 1 is confirmed in the analysis by "Instruct", where environmental strain genotypes are mostly derived from two ancestral populations not found in the dairy isolates. Interestingly, the majority of French dairy isolates are distant from the environmental clades in the two analyses, suggesting a considerable lapse of time between domestication and the present-day cheese-making strains, with little genetic transfer (or transfer of strains) between the domesticated and environmental gene pools, or otherwise domestication from an environmental source geographically distant from France.

MLST or microsatellite typing methods have been used in many studies in the past. However, if discrimination between populations was often successful, correlations between the genotyping and the origin or the technological capabilities of the species studied were more difficult to detect. Microsatellite typing has proved very successful with the model species $S$. cerevisiae, since correlations between the technological activities and/or the geographic origin were observed [10] and later confirmed and extended by several genomic studies [11,12,14,34,38-40]. 
An ideal typing system would allow discrimination of each isolate while allowing the tracing of the underlying ancestry linking groups of strains. In practice phylogenetic trees are a compromise between these two, often contradictory objectives. The present microsatellite analysis clearly shows meaningful phylogenetic relationships, clustering individuals into coherent groups in relation to use, ecological, and geographical parameters. At the same time, we were able to define 72 genotypes in the collection of 80 isolates, probably a minimal estimate of the discriminatory power of the technique, since some of these, for example CLIB 1251 and CLIB 1252, may well represent the same organism isolated at different times from the same cheese cellar or from nearby locations.

As mentioned above, we detected no general differentiation between geographic origins within dairy yeasts or between the type of technology used in cheese-making, whereas closely related group of oenological strains have been well separated between flor and non-flor populations using microsatellites [14], a separation also confirmed by genomic analysis [39]. A similar situation to that of G. candidum was found for Starmerella bacillaris or for Torulaspora delbrueckii [41] whose oenological strains could be readily differentiated from natural isolates, but for which no specific distinction was made between different vineyards or wineries [20]. In this context, it will be of interest to apply global genomic analysis to G. candidum.

There are several ways in which yeast can adapt to a specific environment: selection for specific positive mutations or rearrangements [42], acquisition of genes through HGT [43-45], or specific retention of genes during evolution [5]. In the last of these studies, it was shown that G. candidum CLIB 918, isolated from St Nectaire cheese, presented 265 specifically retained ancestral genes and 16 genes acquired by HGT, though these genes which distinguished G. candidum from related species were not obviously related to functions or metabolic pathways associated with cheese making. The result of a population genomic study in Geotrichum candidum could shed light on the adaptive mechanism that permitted this yeast species to colonize cheese surface, and help to decipher the role of genes transferred horizontally.

Supplementary Materials: The following are available online at https: / www.mdpi.com/article / 10.3390/microorganisms10010103/s1, Figure S1: Distribution of amplicon lengths for the chosen microsatellite-like loci in the tested strains. Figure S2: Phylogeny of the G. candidum strains, average of random haploid genotypes. Table S1: Microsatellites-like loci chosen for molecular typing: positions, properties and oligonucleotides used for amplification from the genomic DNA. Table S2: Lengths of microsatellite loci, raw data. Table S3, Corrected lengths of microsatellite loci. Table S4: Distribution of alleles within the strains studied.

Author Contributions: Conceptualization, C.R.T., J.-L.L. and S.C.; methodology, C.R.T. and J.-L.L.; formal analysis, C.R.T.; investigation, N.J. and M.L.; resources, C.G.; writing-original draft preparation, C.R.T., J.-L.L. and S.C.; writing-review and editing, C.R.T., J.-L.L. and S.C.; visualization, C.R.T. and J.-L.L.; project administration, J.-L.L. and S.C.; funding acquisition, J.-L.L. and S.C. All authors have read and agreed to the published version of the manuscript.

Funding: This research received no external funding.

Institutional Review Board Statement: Not applicable.

Informed Consent Statement: Not applicable.

Data Availability Statement: Data is presented within this article and Supplementary Material.

Conflicts of Interest: The authors declare no conflict of interest.

\section{References}

1. Boutrou, R.; Guéguen, M. Interests in Geotrichum candidum for cheese technology. Int. J. Food Microbiol. 2005, 102, 1-20. [CrossRef]

2. Fröhlich-Wyder, M.-T.; Arias-Roth, E.; Jakob, E. Cheese yeasts. Yeast 2018, 36, 129-141. [CrossRef]

3. Marcellino, N.; Benson, D.R. The Good, The Bad, and the Ugly: Tales of Mold-Ripened Cheese. In Cheese and Microbes; American Society for Microbiology: Washington, WA, USA, 2014; pp. 95-131. ISBN 978-1-55581-586-8. 
4. $\quad$ Link, H.F. Observationes in Ordines Plantarum Naturales; Dissertatio, I. Magazin Der Gesellschaft Naturforschenden Freunde Berlin: Berlin, Germany, 1809; pp. 3-42.

5. Morel, G.; Sterck, L.; Swennen, D.; Marcet-Houben, M.; Onesime, D.; Levasseur, A.; Jacques, N.; Mallet, S.; Couloux, A.; Labadie, K.; et al. Differential gene retention as an evolutionary mechanism to generate biodiversity and adaptation in yeasts. Sci. Rep. 2015, 5, 11571. [CrossRef]

6. Ladevèze, S.; Haon, M.; Villares, A.; Cathala, B.; Grisel, S.; Herpoël-Gimbert, I.; Henrissat, B.; Berrin, J.-G. The yeast Geotrichum candidum encodes functional lytic polysaccharide monooxygenases. Biotechnol. Biofuels 2017, 10, 215. [CrossRef]

7. Alper, I.; Frenette, M.; Labrie, S. Ribosomal DNA polymorphisms in the yeast Geotrichum candidum. Fungal Biol. 2011, 115, 1259-1269. [CrossRef]

8. Alper, I.; Frenette, M.; Labrie, S. Genetic diversity of dairy Geotrichum candidum strains revealed by multilocus sequence typing. Appl. Microbiol. Biotechnol. 2013, 97, 5907-5920. [CrossRef]

9. Jacques, N.; Mallet, S.; Laaghouiti, F.; Tinsley, C.R.; Casaregola, S. Specific populations of the yeast Geotrichum candidum revealed by molecular typing. Yeast 2017, 34, 165-178. [CrossRef]

10. Legras, J.-L.; Merdinoglu, D.; Cornuet, J.-M.; Karst, F. Bread, beer and wine: Saccharomyces cerevisiae diversity reflects human history. Mol. Ecol. 2007, 16, 2091-2102. [CrossRef]

11. Liti, G.; Carter, D.M.; Moses, A.M.; Warringer, J.; Parts, L.; James, S.A.; Davey, R.P.; Roberts, I.N.; Burt, A.; Koufopanou, V.; et al Population genomics of domestic and wild yeasts. Nature 2009, 458, 337-341. [CrossRef]

12. Peter, J.; De Chiara, M.; Friedrich, A.; Yue, J.-X.; Pflieger, D.; Bergström, A.; Sigwalt, A.; Barre, B.; Freel, K.; Llored, A.; et al. Genome evolution across 1,011 Saccharomyces cerevisiae isolates. Nature 2018, 556, 339-344. [CrossRef]

13. Masneuf-Pomarede, I.; Salin, F.; Börlin, M.; Coton, E.; Coton, M.; Le Jeune, C.; Legras, J.-L. Microsatellite analysis ofSaccharomyces uvarumdiversity. FEMS Yeast Res. 2016, 16, fow002. [CrossRef]

14. Legras, J.-L.; Erny, C.; Charpentier, C. Population Structure and Comparative Genome Hybridization of European Flor Yeast Reveal a Unique Group of Saccharomyces cerevisiae Strains with Few Gene Duplications in Their Genome. PLoS ONE 2014, 9, e108089. [CrossRef]

15. Martiniuk, J.T.; Pacheco, B.; Russell, G.; Tong, S.; Backstrom, I.; Measday, V. Impact of Commercial Strain Use on Saccharomyces cerevisiae Population Structure and Dynamics in Pinot Noir Vineyards and Spontaneous Fermentations of a Canadian Winery. PLoS ONE 2016, 11, e0160259. [CrossRef]

16. Tapsoba, F.; Legras, J.-L.; Savadogo, A.; Dequin, S.; Traore, A.S. Diversity of Saccharomyces cerevisiae strains isolated from Borassus akeassii palm wines from Burkina Faso in comparison to other African beverages. Int. J. Food Microbiol. 2015, 211, 128-133. [CrossRef]

17. Bi, C.Y.T.; Amoikon, T.L.; Kouakou, C.A.; Noemie, J.; Lucas, M.; Grondin, C.; Legras, J.-L.; N'Guessan, F.K.; Djeni, T.N.; Djè, M.K.; et al. Genetic diversity and population structure of Saccharomyces cerevisiae strains isolated from traditional alcoholic beverages of Côte d'Ivoire. Int. J. Food Microbiol. 2019, 297, 1-10. [CrossRef]

18. Albertin, W.; Setati, M.E.; Miot-Sertier, C.; Mostert, T.T.; Colonna-Ceccaldi, B.; Coulon, J.; Girard, P.; Moine, V.; Pillet, M.; Salin, F.; et al. Hanseniaspora uvarum from Winemaking Environments Show Spatial and Temporal Genetic Clustering. Front. Microbiol. 2016, 6, 1569. [CrossRef]

19. Ezeronye, O.; Legras, J.-L. Genetic analysis of Saccharomyces cerevisiaes trains isolated from palm wine in eastern Nigeria. Comparison with other African strains. J. Appl. Microbiol. 2009, 106, 1569-1578. [CrossRef]

20. Masneuf-Pomarede, I.; Juquin, E.; Miot-Sertier, C.; Renault, P.; Laizet, Y.; Salin, F.; Alexandre, H.; Capozzi, V.; Cocolin, L.; ColonnaCeccaldi, B.; et al. The yeast Starmerella bacillaris (synonym Candida zemplinina) shows high genetic diversity in winemaking environments. FEMS Yeast Res. 2015, 15, fov045. [CrossRef]

21. Tapsoba, F.; Savadogo, A.; Legras, J.; Zongo, C.; Traore, A.S. Microbial diversity and biochemical characteristics of Borassus akeassii wine. Lett. Appl. Microbiol. 2016, 63, 297-306. [CrossRef]

22. Edwards, A.W.F. Distances between Populations on the Basis of Gene Frequencies. Biometrics 1971, 27, 873. [CrossRef]

23. Kamvar, Z.N.; Tabima, J.F.; Grünwald, N.J. Poppr: An R package for genetic analysis of populations with clonal, partially clonal, and/or sexual reproduction. PeerJ 2014, 2, e281. [CrossRef]

24. R Foundation for Statistical Computing R: A Language and Environment for Statistical Computing. Available online: https: //www.R-project.org/ (accessed on 11 March 2021).

25. R Studio Team. RStudio: Integrated Development for R; RStudio, Inc.: Boston, MA, USA, 2016. Available online: http://www. rstudio.com/ (accessed on 11 March 2021).

26. Kumar, S.; Stecher, G.; Li, M.; Knyaz, C.; Tamura, K. MEGA X: Molecular Evolutionary Genetics Analysis across Computing Platforms. Mol. Biol. Evol. 2018, 35, 1547-1549. [CrossRef]

27. Gao, H.; Williamson, S.; Bustamante, C.D. A Markov Chain Monte Carlo Approach for Joint Inference of Population Structure and Inbreeding Rates from Multilocus Genotype Data. Genetics 2007, 176, 1635-1651. [CrossRef]

28. Jakobsson, N.; Rosenberg, N.A. CLUMPP: A Cluster Matching and Permutation Program for Dealing with Label Switching and Multimodality in Analysis of Population Structure. Bioinformatics 2007, 23, 1801-1806. [CrossRef]

29. Mantel, N. The detection of disease clustering and a generalized regression approach. Cancer Res. 1967, 27, 209-220.

30. de Vienne, D.M.; Giraud, T.; Martin, O.C. A congruence index for testing topological similarity between trees. Bioinformatics 2007, 23, 3119-3124. [CrossRef] 
31. Morel, G. La levure Geotrichum Candidum: Taxonomie, Biodiversité et Génome. Ph.D. Thesis, Université Paris Sud-Paris XI, Orsay, France, 2012.

32. de Hoog, G.S.; Smith, M.-T. Galactomyces Redhead \& Malloch. In The Yeasts: A Taxonomic Study; Kurtzman, C.P., Ed.; Elsevier: Amsterdam, The Netherlands, 2011; pp. 413-420. ISBN 978-0-444-52149-1.

33. Sztajer, H.; Wang, W.; Lünsdorf, H.; Stocker, A.; Schmid, R.D. Purification and some properties of a novel microbial lactate oxidase. Appl. Microbiol. Biotechnol. 1996, 45, 600-606. [CrossRef]

34. Schacherer, J.; Shapiro, J.A.; Ruderfer, D.M.; Kruglyak, L. Comprehensive polymorphism survey elucidates population structure of Saccharomyces cerevisiae. Nat. Cell Biol. 2009, 458, 342-345. [CrossRef]

35. Pritchard, J.K.; Stephens, M.; Donnelly, P. Inference of population structure using multilocus genotype data. Genetics 2000, 155, 945-959. Available online: http:/ / www.ncbi.nlm.nih.gov/pubmed/10835412 (accessed on 9 December 2021). [CrossRef]

36. Gente, S.; Desmasures, N.; Panoff, J.-M.; Gueguen, M. Genetic diversity among Geotrichum candidum strains from various substrates studied using RAM and RAPD-PCR. J. Appl. Microbiol. 2002, 92, 491-501. [CrossRef]

37. Perkins, V.; Vignola, S.; Lessard, M.-H.; Plante, P.-L.; Corbeil, J.; Dugat-Bony, E.; Frenette, M.; Labrie, S. Phenotypic and Genetic Characterization of the Cheese Ripening Yeast Geotrichum candidum. Front. Microbiol. 2020, 11, 737. [CrossRef]

38. Almeida, P.; Barbosa, R.; Zalar, P.; Imanishi, Y.; Shimizu, K.; Turchetti, B.; Legras, J.-L.; Serra, M.; Dequin, S.; Couloux, A.; et al. A population genomics insight into the Mediterranean origins of wine yeast domestication. Mol. Ecol. 2015, 24, 5412-5427. [CrossRef]

39. Coi, A.L.; Bigey, F.; Mallet, S.; Marsit, S.; Zara, G.; Gladieux, P.; Galeote, V.; Budroni, M.; Dequin, S.; Legras, J.L. Genomic signatures of adaptation to wine biological ageing conditions in biofilm-forming flor yeasts. Mol. Ecol. 2017, 26, 2150-2166. [CrossRef]

40. Legras, J.-L.; Galeote, V.; Bigey, F.; Camarasa, C.; Marsit, S.; Nidelet, T.; Sanchez, I.; Couloux, A.; Guy, J.; Franco-Duarte, R.; et al. Adaptation of S. cerevisiae to Fermented Food Environments Reveals Remarkable Genome Plasticity and the Footprints of Domestication. Mol. Biol. Evol. 2018, 35, 1712-1727. [CrossRef]

41. Albertin, W.; Chasseriaud, L.; Comte, G.; Panfili, A.; Delcamp, A.; Salin, F.; Marullo, P.; Bely, M. Winemaking and Bioprocesses Strongly Shaped the Genetic Diversity of the Ubiquitous Yeast Torulaspora delbrueckii. PLoS ONE 2014, 9, e94246. [CrossRef]

42. Pérez-Ortín, J.E.; Querol, A.; Puig, S.; Barrio, E. Molecular Characterization of a Chromosomal Rearrangement Involved in the Adaptive Evolution of Yeast Strains. Genome Res. 2002, 12, 1533-1539. [CrossRef]

43. Novo, M.; Bigey, F.; Beyne, E.; Galeote, V.; Gavory, F.; Mallet, S.; Cambon, B.; Legras, J.-L.; Wincker, P.; Casaregola, S.; et al. Eukaryote-to-eukaryote gene transfer events revealed by the genome sequence of the wine yeast Saccharomyces cerevisiae EC1118. Proc. Natl. Acad. Sci. USA 2009, 106, 16333-16338. [CrossRef]

44. Marsit, S.; Sanchez, I.; Galeote, V.; Dequin, S. Horizontally acquired oligopeptide transporters favour adaptation of Saccharomyces cerevisiae wine yeast to oenological environment. Environ. Microbiol. 2016, 18, 1148-1161. [CrossRef]

45. Almeida, P.; Barbosa, R.; Bensasson, D.; Gonçalves, P.; Sampaio, J. Adaptive divergence in wine yeasts and their wild relatives suggests a prominent role for introgressions and rapid evolution at noncoding sites. Mol. Ecol. 2017, 26, 2167-2182. [CrossRef] 